\title{
Mural Endocarditis: The GAMES Registry Series and Review of the Literature
}

\author{
Andrea Gutiérrez-Villanueva · Patricia Muñoz · Antonia Delgado-Montero • María Olmedo-Samperio • \\ Arístides de Alarcón · Encarnación Gutiérrez-Carretero · Jesús Zarauza · Delia García i Pares · \\ Miguel Ángel Goenaga · Guillermo Ojeda-Burgos • Ane Josune Goikoetxea-Agirre • \\ José $\mathrm{M}^{\mathrm{a}}$ Reguera-Iglesias · Antonio Ramos · Ana Fernández-Cruz (D) on behalf of Spanish Collaboration on \\ Endocarditis-Grupo de Apoyo al Manejo de la Endocarditis infecciosa en España (GAMES)
}

Received: May 7, 2021 / Accepted: June 22, 2021 / Published online: July 26, 2021

(C) The Author(s) 2021

\section{ABSTRACT}

Introduction: Mural infective endocarditis (MIE) is a rare type of endovascular infection. We present a comprehensive series of patients with mural endocarditis.

Methods: Patients with infectious endocarditis (IE) from 35 Spanish hospitals were

Supplementary Information The online version contains supplementary material available at https:// doi.org/10.1007/s40121-021-00490-y.

A. Gutiérrez-Villanueva

Internal Medicine Department, Hospital

Universitario Puerta de Hierro-Majadahonda,

Madrid, Spain

P. Muñoz · M. Olmedo-Samperio

Clinical Microbiology and Infectious Diseases

Department, Hospital General Universitario

Gregorio Marañón, Madrid, Spain

P. Muñoz $\cdot$ M. Olmedo-Samperio

Instituto de Investigación Sanitaria Gregorio

Marañón, Madrid, Spain

P. Muñoz $\cdot$ M. Olmedo-Samperio

CIBER Enfermedades Respiratorias-CIBERES (CB06/

06/0058), Madrid, Spain

P. Muñoz $\cdot$ M. Olmedo-Samperio

Facultad de Medicina, Universidad Complutense de

Madrid, Madrid, Spain

A. Delgado-Montero

Echo-Cardiology Unit. Hospital General

Universitario Gregorio Marañón, Madrid, Spain prospectively included in the GAMES registry between 2008 and 2017. MIEs were compared to non-MIEs. We also performed a literature search for cases of MIE published between 1979 and 2019 and compared them to the GAMEs series. Results: Twenty-seven MIEs out of 3676 IEs were included. When compared to valvular IE (VIE) or device-associated IE (DIE), patients with MIE were younger (median age 59 years, $p<0.01)$. Transplantation $(18.5 \%$ versus $1.6 \%$ VIE and $2 \%$ DIE, $p<0.01)$, hemodialysis $(18.5 \%$ versus $4.3 \%$ VIE and $4.4 \%$ DIE, $p=0.006)$,
A. de Alarcón
Clinical Unit of Infectious Diseases, Microbiology, and Preventive Medicine, Infectious Diseases Research Group, Institute of Biomedicine of Seville (IBiS), University of Seville/CSIC/University Hospital Virgen del Rocío, Seville, Spain

\section{E. Gutiérrez-Carretero}
Cardiac Surgery Department, CIBERCV, Institute of Biomedicine of Seville (IBiS), University of Seville/ CSIC/University Hospital Virgen del Rocío, Seville, Spain

\section{J. Zarauza \\ Cardiology Department, Hospital Universitario \\ Marqués de Valdecilla, Santander, Spain}
D. García i Pares
Infectious Diseases Service, Hospital Clinic-IDIBAPS, University of Barcelona, Barcelona, Spain
D. García i Pares
Internal Medicine Service, Clinica Sagrada Familia, Barcelona, Spain 
catheter source $(59.3 \%$ versus $9.7 \%$ VIE and $8.8 \%$ DIE, $p<0.01)$ and Candida etiology (22.2\% versus $2 \%$ DIE and $1.2 \%$ VIE, $p<0.01$ ) were more common in MIE, whereas the Charlson Index was lower (4 versus 5 in nonMIE, $p=0.006)$. Mortality was similar.MIE from the literature shared many characteristics with MIE from GAMES, although patients were younger ( 45 years vs. 56 years, $p<0.001$ ), the Charlson Index was lower (1.3 vs. 4.3, $p=0.0001)$, catheter source was less common (13.9\% vs. $59.3 \%)$ and there were more IVDUs ( $25 \%$ vs. $3.7 \%$ ). S. aureus was the most frequent microorganism (50\%, $p=0.035)$. Systemic complications were more common but mortality was similar.

Conclusion: MIE is a rare entity. It is often a complication of catheter use, particularly in immunocompromised and hemodialysis patients. Fungal etiology is common. Mortality is similar to other IEs.

Keywords: Endocarditis; Mural; Non-valvular endocarditis

M. Á. Goenaga

Infectious Diseases Department, Hospital

Universitario Donosti, ISS Biodonostia, San

Sebastián, Spain

G. Ojeda-Burgos

Infectious Diseases Clinical Unit, Hospital

Universitario Virgen de La Victoria, Málaga, Spain

A. J. Goikoetxea-Agirre

Infectious Diseases Department, Hospital

Universitario de Cruces, Bilbao, Spain

J. M. Reguera-Iglesias

Infectious Diseases Department, Hospital Regional

Universitario de Málaga, Málaga, Spain

A. Ramos · A. Fernández-Cruz ( $\square)$

Infectious Diseases Unit, Internal Medicine

Department, Hospital Puerta de Hierro-

Majadahonda, Madrid, Spain

e-mail: anafcruz999@gmail.com

\section{Key Summary Points}

Mural endocarditis is a rare but increasingly recognized health careassociated disease that requires a high index of suspicion and a multidisciplinary approach to avoid a relevant morbidity and mortality.

It is associated with intravascular catheter use and immunocompromised patients such as transplantation, cancer and hemodialysis patients.

Fungal etiology and large vegetations are common in mural endocarditis.

\section{INTRODUCTION}

Mural infective endocarditis (MIE) is a rare type of endovascular infection that involves the nonvalvular endocardium [1-6]. Cases of MIE have been described in Candida and Aspergillus endocarditis [2, 7-12] as well as in infective endocarditis (IE) caused by other microorganisms more characteristic of valvular endocarditis (VIE) such as Staphylococcus aureus and Streptococcus. Others have described MIE in intravenous drug users or associated with catheter use [1, 5, 7, 13-17].

Since valves are not involved, diagnosis is often delayed and made only when complications such as systemic or pulmonary embolisms occur, conveying a significant morbidity and mortality. Prognosis of MIE is usually poor according to the literature $[3,5,18]$.

Information about MIE comes from isolated case reports or short series of selected cases. The actual epidemiology, relevance and prognosis are unknown. Data on MIE management and outcome are lacking.

We present a series of MIEs from the prospective GAMES registry and a comprehensive review of the literature. 


\section{METHODS}

\section{Study design}

Between January 2008 and June 2018, consecutive patients with IE according to the Duke criteria were prospectively included in the "Spanish Collaboration on EndocarditisGrupo de Apoyo al Manejo de la Endocarditis Infecciosa en España (GAMES)" registry, which is maintained by 35 Spanish hospitals. Multidisciplinary teams evaluated every case and completed standardized case report forms for each IE episode, including clinical, microbiologic and echocardiographic sections and follow-up data.

\section{Literature search}

Additionally, we performed a PubMed search that included the search term: "mural endocarditis." We filtered case reports and case series and omitted cases that included valvular or intracardiac device involvement. Inappropriate and inaccessible posts were excluded. A standardized form adapted from that of the GAMES registry was filled in for each literature MIE with enough available information and included in a database. The list of cases included in the literature review is accessible in Supplementary material.

\section{Definitions}

We considered MIE cases with non-valvular endocardium involvement. Cases with both mural and valvular involvement were excluded from the analysis, as were cases of endovascular infection that could be considered endarteritis (involving great vessels, ductus arteriosus, etc.). We considered as non-mural endocarditis those cases of infective endocarditis that involved valvular endocardial surfaces [valvular endocarditis (VIE) or those with vegetations involving intra-cardiac devices (pacemakers, implantable cardioverter defibrillators) deviceassociated endocarditis (DIE)]. IE was defined according to the modified Duke criteria [19].
Age-adjusted Charlson Comorbidity Index was used to quantify comorbidities [20].

Place of acquisition of IE was defined following ICE recommendations [21].

The catheter was considered as the source of endocarditis when the etiologic microorganism was detected in both the catheter and the blood cultures or surgical samples (vegetation, valve or implantable device), or when, from a clinical standpoint, the treating physician considered the catheter was the source.

All patients were evaluated by cardiac surgeons to determine the need for surgery according to international indications [22]. The final decision on surgery was made in agreement with the multidisciplinary endocarditis team at each center.

Both in-hospital mortality (overall mortality rate during the hospital stay) and 1-year mortality were analyzed.

\section{Data analysis}

Cases with MIE were compared to cases with non-valvular endocarditis in the GAMES registry (both VIE and DIE). MIEs from the GAMES registry were compared to cases of MIE from the literature.

The quantitative variables were expressed as mean and standard deviation or median and interquartile range; qualitative variables were expressed as frequency and percentage. Continuous variables were compared using the $t$ test, and categorical variables were compared using the $\chi^{2}$ test or Fisher's exact test when the $\chi^{2}$ test was not appropriate.

All statistical analyses were performed with SPSS version 25 software (IBM SPSS Statistics 22.0, Armonk, New York, NY: IBM Corp.).

\section{Ethics}

The study and the common case report form were approved by the local and national institutional review boards and ethics committees (Comité ético de Investigación Clínica Regional de la Comunidad de Madrid CEIC-R; EC 18/07; date 11/01/2008). 


\section{RESULTS}

During the study period 3767 patients were included. Of them, 27 MIE $(0.7 \%$ of total endocarditis) and 3649 non-mural endocarditis [407 (11.1\%) DIE and 3242 (88.2\%) VIE] were registered in the GAMES database. Moreover, 36 cases from the literature review that provided enough information to analyze were selected.

\section{Differences between mural and non-mural endocarditis in the GAMES registry}

General characteristics of mural (Fig. 1) and non-mural endocarditis from the GAMES registry are displayed in Table 1.

Compared to non-MIE, patients with MIE were significantly younger, and MIE was more prevalent in women. Patients with MIE presented a lower age-adjusted Charlson Comorbidity Index, were receiving hemodialysis more often and transplantation was more frequent as underlying disease.
Furthermore, in contrast with VIEs, which were mainly community-acquired $(61.7 \%)$, the majority of MIEs were hospital-acquired (63\%). DIEs were more common in a nosocomial setting and related to medical care.

A striking difference was found in the proportion of MIEs originating from the catheter, which was very high (59.3\%) compared to nonMIEs with catheter source $(8.8 \%$ and $9.7 \%$ in DIE and VIE, respectively) $(p<0.01)$.

The microorganisms most frequently implicated in endocarditis in all groups were Staphylococci, with a prevalence in MIEs of $29.6 \%$, being $14.8 \% S$. aureus and $S$. coagulase negative each, followed by Streptococci (25.9\%). Streptococci were significantly more frequent in MIE and VIE (27.5\%) than in DIE (8.1\%). Significant differences were found between groups regarding Candida etiology (22.2\% among MIE versus $2 \%$ in DIE and $1.2 \%$ in VIE, $p<0.01$ ). Aspergillus was more common in MIE, though without statistical significance $(3.7 \%$ among MIE vs. $0.2 \%$ in DIE and $0.3 \%$ in VIE, $p=0.144$ ).

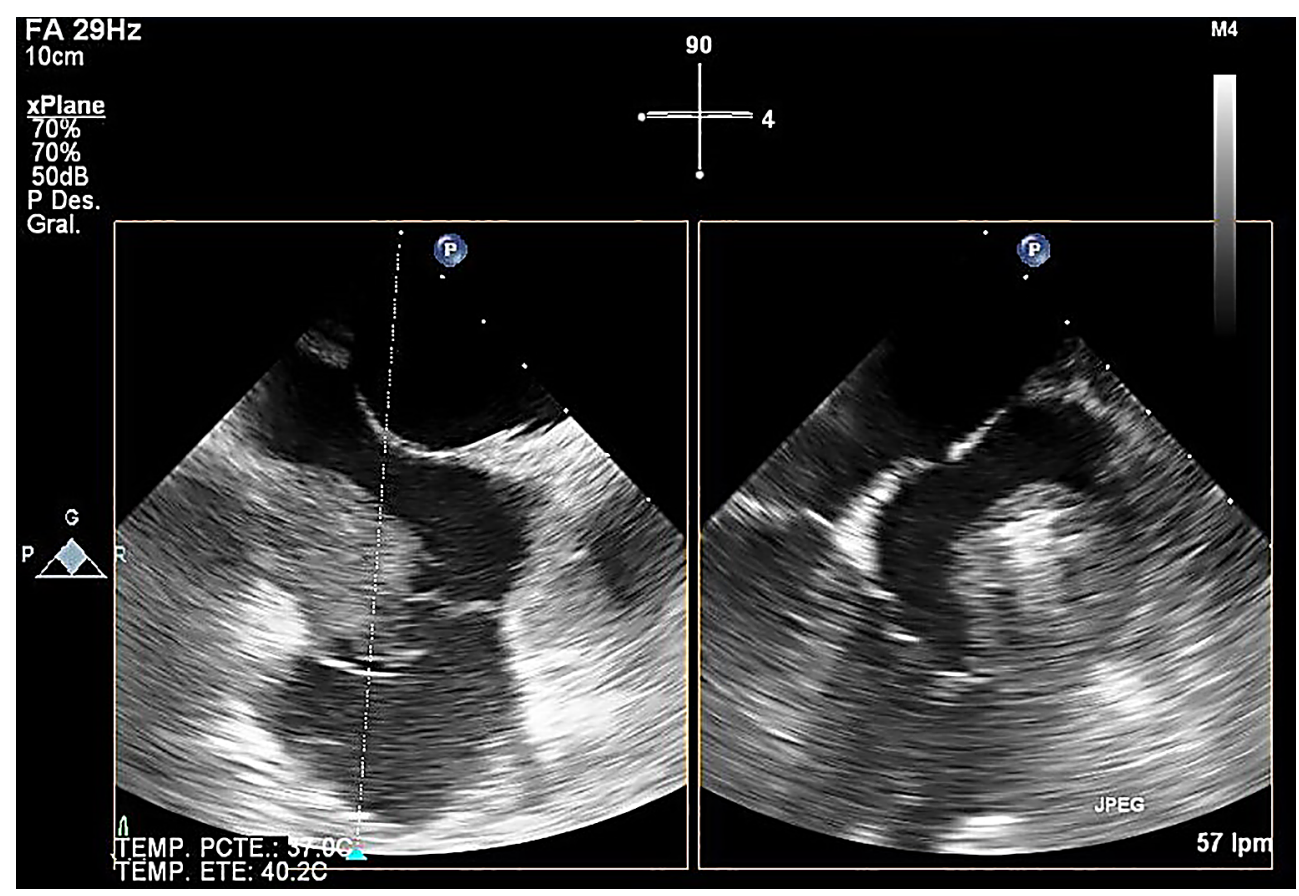

Fig. 1 Simultaneous bi-plane imaging by transesophageal echo showing a large sessile heterogeneous mass $(3.9 \times 2.8 \mathrm{~cm})$ attached to the lateral and inferior wall of the right atrium, with irregular contour. The tricuspid valve and inferior vena cava were not affected 
Table 1 Infective endocarditis in the GAMES registry: mural compared to valvular and device-associated endocarditis

\begin{tabular}{|c|c|c|c|c|}
\hline Variables & $\begin{array}{l}\text { A } \\
\text { Mural (MIE) } \\
(N=27)\end{array}$ & $\begin{array}{l}\text { B } \\
\text { Device (DIE) } \\
(N=407)\end{array}$ & $\begin{array}{l}\mathrm{C} \\
\text { Valvular }(\mathrm{VIE})(N=3242)\end{array}$ & $p$ value \\
\hline Age, median (IQR) & $59(46-67)$ & $71(62-79)$ & $69(57-77)$ & $<0.01^{\text {a.c }}$ \\
\hline Sex (male) & $11(40.7)$ & $297(72.9)$ & $2160(66.6)$ & $0.001^{\mathrm{a}}$ \\
\hline Lung disease & $8(29.6)$ & $94(23.0)$ & $570(17.5)$ & 0.167 \\
\hline Coronary disease & $5(18.5)$ & $149(36.6)$ & $809(24.9)$ & 0.09 \\
\hline Heart failure & $10(37.0)$ & $194(47.7)$ & $1022(31.5)$ & $0.001^{\mathrm{b}}$ \\
\hline Diabetes & $3(11.1)$ & $154(37.8)$ & $892(27.5)$ & $0.009^{\mathrm{a}}$ \\
\hline Trasplantation & $5(18.5)$ & $8(2.0)$ & $54(1.6)$ & $<0.01^{\text {a.c }}$ \\
\hline Heart & $2(7.4)$ & $1(0.2)$ & $3(0.1)$ & $0.002^{\mathrm{a}, \mathrm{c}}$ \\
\hline Lung & 0 & 0 & $3(0.1)$ & 0.761 \\
\hline $\mathrm{PM} / \mathrm{ICD}$ & $2(7.4)$ & $407(100.0)$ & $262(8.0)$ & $<0.01^{\mathrm{a} . \mathrm{b}}$ \\
\hline Peripheral arterial disease & $2(7.4)$ & $49(12.0)$ & $341(10.5)$ & 0.678 \\
\hline Cerebrovascular disease & $3(11.1)$ & $43(10.6)$ & $435(13.4)$ & 0.946 \\
\hline Neoplasm & $6(22.2)$ & $36(8.8)$ & $528(16.2)$ & $0.001^{b}$ \\
\hline Congenital cardiopathy & $3(11.1)$ & $16(3.9)$ & $181(5.5)$ & 0.202 \\
\hline Prior kidney disease & $8(29.6)$ & $127(31.2)$ & $766(23.6)$ & $0.001^{\mathrm{b}}$ \\
\hline Prior hemodialysis & $5(18.5)$ & $18(4.4)$ & $140(4.3)$ & $0.006^{\text {a.c }}$ \\
\hline Liver disease & $3(11.1)$ & $20(4.9)$ & $352(10.8)$ & $0.003^{b}$ \\
\hline IVDU & $1(3.7)$ & 0 & $78(2.4)$ & 0.847 \\
\hline Age-adjusted-Charlson Index & $4(2-6)$ & $5(3-7)$ & $5(3-7)$ & $0.006^{\text {a.c }}$ \\
\hline \multicolumn{5}{|l|}{ Place of acquisition } \\
\hline Community acquired & $7(25.9)$ & $156(38.2)$ & $2001(61.7)$ & $0.007^{b . c}$ \\
\hline Hospital acquired & $17(63.0)$ & $184(45.2)$ & $874(26.9)$ & $<0.01^{\text {b.c }}$ \\
\hline Health care associated & $3(11.1)$ & $46(11.3)$ & $250(7.7)$ & 0.766 \\
\hline Catheter source & $16(59.3)$ & $36(8.8)$ & $313(9.7)$ & $<0.01^{\text {a.c }}$ \\
\hline \multicolumn{5}{|l|}{ Etiology } \\
\hline Staphylococcus aureus & $4(14.8)$ & $125(30.7)$ & $708(21.8)$ & $<0.01^{\mathrm{b}}$ \\
\hline CNS & $4(14.8)$ & $123(30.2)$ & $515(15.9)$ & $<0.01^{\mathrm{b}}$ \\
\hline Enterococcus & $1(3.7)$ & $20(4.9)$ & $482(14.9)$ & $<0.01^{\mathrm{b}}$ \\
\hline Streptococcus & $7(25.9)$ & $33(8.1)$ & $893(27.5)$ & $<0.01^{a . b}$ \\
\hline Candida & $6(22.2)$ & $8(2.0)$ & $39(1.2)$ & $<0.01^{\mathrm{a} . \mathrm{c}}$ \\
\hline
\end{tabular}


Table 1 continued

\begin{tabular}{|c|c|c|c|c|}
\hline Variables & $\begin{array}{l}\text { A } \\
\text { Mural (MIE) } \\
(N=27)\end{array}$ & $\begin{array}{l}\text { B } \\
\text { Device (DIE) } \\
(N=407)\end{array}$ & $\begin{array}{l}\mathrm{C} \\
\text { Valvular (VIE) }(N=3242)\end{array}$ & $p$ value \\
\hline Unknown etiology & 0 & $35(8.6)$ & $296(9.1)$ & 0.795 \\
\hline Enterobacteriaceae & $2(7.4)$ & $10(2.4)$ & $69(2.1)$ & 0.225 \\
\hline Neisseria spp. & 0 & 0 & $2(0.6)$ & 0.533 \\
\hline Aspergillus spp & $1(3.7)$ & $1(0.2)$ & $9(0.3)$ & 0.144 \\
\hline Polymicrobial & $2(7.4)$ & $17(4.1)$ & $45(1.4)$ & 0.071 \\
\hline \multicolumn{5}{|l|}{ Clinical characteristic } \\
\hline Vegetation size (mm), median (IQR) & $22(8-39)$ & $12(7-18)$ & $10(7-16)$ & $<0.01^{\text {a.c }}$ \\
\hline Intracardiac complication & $1(3.7)$ & $15(3.7)$ & $1099(33.9)$ & $<0.01^{\text {b.c }}$ \\
\hline Perforation/rupture & 0 & $7(1.7)$ & $495(15.2)$ & $<0.01^{\mathrm{b}}$ \\
\hline Pseudoaneurysm & 0 & 0 & $199(6.1)$ & $<0.01^{\mathrm{b}}$ \\
\hline Abscess & 0 & $6(1.4)$ & $557(17.1)$ & $<0.01^{\mathrm{b}}$ \\
\hline Intracardiac fistula & 0 & $1(0.2)$ & $88(2.7)$ & $0.004^{\mathrm{b}}$ \\
\hline Vascular phenomena & $3(11.1)$ & $9(2.2)$ & $310(9.5)$ & $0.033^{\mathrm{a} . \mathrm{b}}$ \\
\hline Heart murmur & $4(14.8)$ & $35(8.6)$ & $1225(37.7)$ & $0.001^{b . c}$ \\
\hline Heart failure & $5(18.5)$ & $76(18.6)$ & $1383(42.6)$ & $<0.01^{\text {b.c }}$ \\
\hline Persistent bacteremia & $5(18.5)$ & $51(12.5)$ & $374(11.5)$ & 0.408 \\
\hline Central nervous system involvement & $1(3.7)$ & $18(4.4)$ & $705(21.7)$ & $0.041^{\text {b.c }}$ \\
\hline Embolism & $6(22.2)$ & $60(14.7)$ & $683(21.0)$ & $0.003^{\mathrm{b}}$ \\
\hline Kidney failure & $5(18.5)$ & $140(34.3)$ & $1175(36.2)$ & 0.087 \\
\hline Septic shock & $5(18.5)$ & $34(8.3)$ & $416(12.8)$ & 0.173 \\
\hline Sepsis & $3(11.1)$ & $54(13.2)$ & $552(17.0)$ & 0.576 \\
\hline Surgical indication & $9(33.3)$ & $337(82.8)$ & $2102(65.3)$ & $<0.01^{\text {a.b.c }}$ \\
\hline Cardiac surgery & $5(18.5)$ & $314(77.1)$ & $1382(42.6)$ & $<0.01^{\text {a.b.c }}$ \\
\hline In-hospital mortality & $5(18.5)$ & $58(14.3)$ & $913(28.2)$ & $<0.01^{\mathrm{b}}$ \\
\hline 1-year mortality & $2(7.4)$ & $22(5.4)$ & $206(6.3)$ & 0.863 \\
\hline
\end{tabular}

a Significant differences between A-B

b Significant differences between B-C

c Significant differences between A-C 
Table 2 Mural infective endocarditis: GAMES registry versus literature review

\begin{tabular}{|c|c|c|c|c|}
\hline Variables (\%) & $\begin{array}{l}\text { Games } \\
(N=27)(\%)\end{array}$ & Literature $(N=36)(\%)$ & $p$ value & $\begin{array}{l}\text { Total } \\
(N=63)\end{array}$ \\
\hline Age, median (IQR) & $56(46-67)$ & $45(29-57)$ & 0.001 & $52.5(35.3-64)$ \\
\hline Sex (male) & $11(40.7)$ & $22(61.1)$ & 0.132 & $33(52.3)$ \\
\hline Lung disease & $8(29.7)$ & $2(5.6)$ & 0.011 & $10(16.4)$ \\
\hline Coronary disease & $5(18.5)$ & $0(0)$ & 0.010 & $5(7.9)$ \\
\hline Heart failure & $10(37)$ & $0(0)$ & 0.000 & $10(15.8)$ \\
\hline Diabetes & $3(11.1)$ & $3(8.3)$ & 1.000 & $6(9.5)$ \\
\hline Trasplantation & $5(18.5)$ & $1(2.8)$ & 0.076 & $6(9.5)$ \\
\hline Heart & $2(7.4)$ & 0 & & $2(33.3)$ \\
\hline Kidney & 0 & $1(2.8)$ & & $1(16.7)$ \\
\hline $\mathrm{PM} / \mathrm{ICD}$ & $2(7.4)$ & $0(0)$ & 0.180 & $2(3.1)$ \\
\hline Peripheral arterial disease & $2(7.4)$ & $1(2.8)$ & 0.572 & $3(4.8)$ \\
\hline Cerebrovascular disease & $3(11.1)$ & $1(2.8)$ & 0.305 & $4(6.3)$ \\
\hline Neoplasm & $6(22.2)$ & $4(11.1)$ & 0.303 & $10(15.9)$ \\
\hline Congenital cardiopathy & $3(11.1)$ & $4(11.1)$ & 1.000 & $7(11.1)$ \\
\hline Prior kidney disease & $8(29.6)$ & $2(5.6)$ & 0.014 & $10(15.9)$ \\
\hline Prior hemodialysis & $5(18.5)$ & $1(2.8)$ & 0.076 & $6(9.5)$ \\
\hline Liver disease & $3(11.1)$ & $6(16.7)$ & 0.720 & $9(14.3)$ \\
\hline IVDU & $1(3.7)$ & $9(25)$ & 0.034 & $10(15.9)$ \\
\hline Age-adjusted Charlson Index & $4.3(\mathrm{DE} 2.7)$ & $1.3(\mathrm{DE} 2.2)$ & 0.000 & 2.7 \\
\hline Place of acquisition & & & 0.0001 & \\
\hline Community acquired & $7(25.9)$ & $25(69.4)$ & & $32(50.8)$ \\
\hline Hospital acquired & $17(63)$ & $5(13.9)$ & & $22(34.9)$ \\
\hline Health care associated & $3(11.1)$ & $6(16.7)$ & & $9(14.3)$ \\
\hline Catheter source & $16(59.3)$ & $5(13.9)$ & 0.000 & $22(34.9)$ \\
\hline Etiology & & & 0.342 & \\
\hline Staphylococcus aureus & $4(14.8)$ & $18(50)$ & 0.035 & $22(34.9)$ \\
\hline CNS & $4(14.8)$ & 0 & 0.074 & $3(4.8)$ \\
\hline Enterococcus & $1(3.7)$ & 0 & 0.429 & $1(1.6)$ \\
\hline Streptococcus & $7(25.9)$ & $8(22.2)$ & 0.772 & $15(23.8)$ \\
\hline Candida & $6(22.2)$ & $3(8.3)$ & 0.155 & $9(14.3)$ \\
\hline Enterobacteriaceae & $2(7.4)$ & $1(2.8)$ & 0.572 & $3(4.8)$ \\
\hline Aspergillus spp & $1(3.7)$ & $4(11.1)$ & 0.381 & $5(7.9)$ \\
\hline
\end{tabular}


Table 2 continued

\begin{tabular}{|c|c|c|c|c|}
\hline Variables (\%) & $\begin{array}{l}\text { Games } \\
(N=27)(\%)\end{array}$ & Literature $(N=36)(\%)$ & $p$ value & $\begin{array}{l}\text { Total } \\
(N=63)\end{array}$ \\
\hline Polymicrobial & $2(7.4)$ & 0 & 0.180 & $2(3.2)$ \\
\hline Unknown etiology & 0 & $2(5.6)$ & 0.502 & $2(3.2)$ \\
\hline \multicolumn{5}{|l|}{ Clinical characteristics } \\
\hline Vegetation size (mm), median (IQR) & $22(8-39)$ & $20(13-33)$ & 0.910 & $22(12-22)$ \\
\hline Vegetation location & & & 0.0001 & \\
\hline Right ventricle & $5(18.5)$ & $9(25)$ & & $14(22.1)$ \\
\hline Left ventricle & $1(3.7)$ & $17(47.2)$ & & $18(28.6)$ \\
\hline Right auricular & $14(51.9)$ & $4(11.1)$ & & $18(28.6)$ \\
\hline Left auricular & $2(7.4)$ & $6(16.7)$ & & $8(12.7)$ \\
\hline Septum & $1(3.7)$ & 0 & & $1(1.6)$ \\
\hline Superior vena cava & $3(11.1)$ & 0 & & $3(4.8)$ \\
\hline Tendinous chords & $1(3.7)$ & 0 & & $1(1.6)$ \\
\hline Intracardiac complication & $1(3.7)$ & $5(13.9)$ & 0.226 & $6(9.5)$ \\
\hline Perforation/rupture & 0 & $2(5.6)$ & 0.502 & $2(3.2)$ \\
\hline Pseudoaneurysm & 0 & $1(2.8)$ & 1.000 & $1(1.6)$ \\
\hline Abscess & 0 & $2(5.6)$ & 0.502 & $2(3.2)$ \\
\hline Intracardiac fistula & 0 & 0 & & $0(0)$ \\
\hline Others & $1(3.7)$ & 0 & & $1(1.6)$ \\
\hline Vascular phenomena & $3(11.1)$ & $8(22.2)$ & 0.332 & $11(17.5)$ \\
\hline Heart murmur & $4(14.8)$ & $5(13.9)$ & 0.207 & $10(15.9)$ \\
\hline Heart failure & $5(18.5)$ & $1(2.8)$ & 0.076 & $6(9.5)$ \\
\hline Persistent bacteremia & $5(18.5)$ & $3(8.3)$ & 0.262 & $8(12.7)$ \\
\hline Central nervus system involvement & $1(3.7)$ & $15(41.7)$ & 0.001 & $16(25.4)$ \\
\hline Embolism & $6(22.2)$ & $24(66.7)$ & 0.002 & $31(49.2)$ \\
\hline Kidney failiure & $5(18.5)$ & $11(30.6)$ & 0.383 & $16(25.4)$ \\
\hline Septic shock & $5(18.5)$ & $10(27.8)$ & 0.552 & $15(23.8)$ \\
\hline Sepsis & $3(11.1)$ & $10(27.8)$ & 0.128 & $13(20.6)$ \\
\hline Surgical indication & $9(33.3)$ & $21(58.3)$ & 0.036 & $30(47.6)$ \\
\hline Cardiac surgery & $5(18.5)$ & $14(38.9)$ & 0.101 & $19(30.2)$ \\
\hline In-hospital mortality & $5(18.5)$ & $9(25)$ & 0.365 & $13(20.6)$ \\
\hline 1-year mortality & $2(7.4)$ & $1(2.8)$ & 0.577 & $3(4.8)$ \\
\hline
\end{tabular}




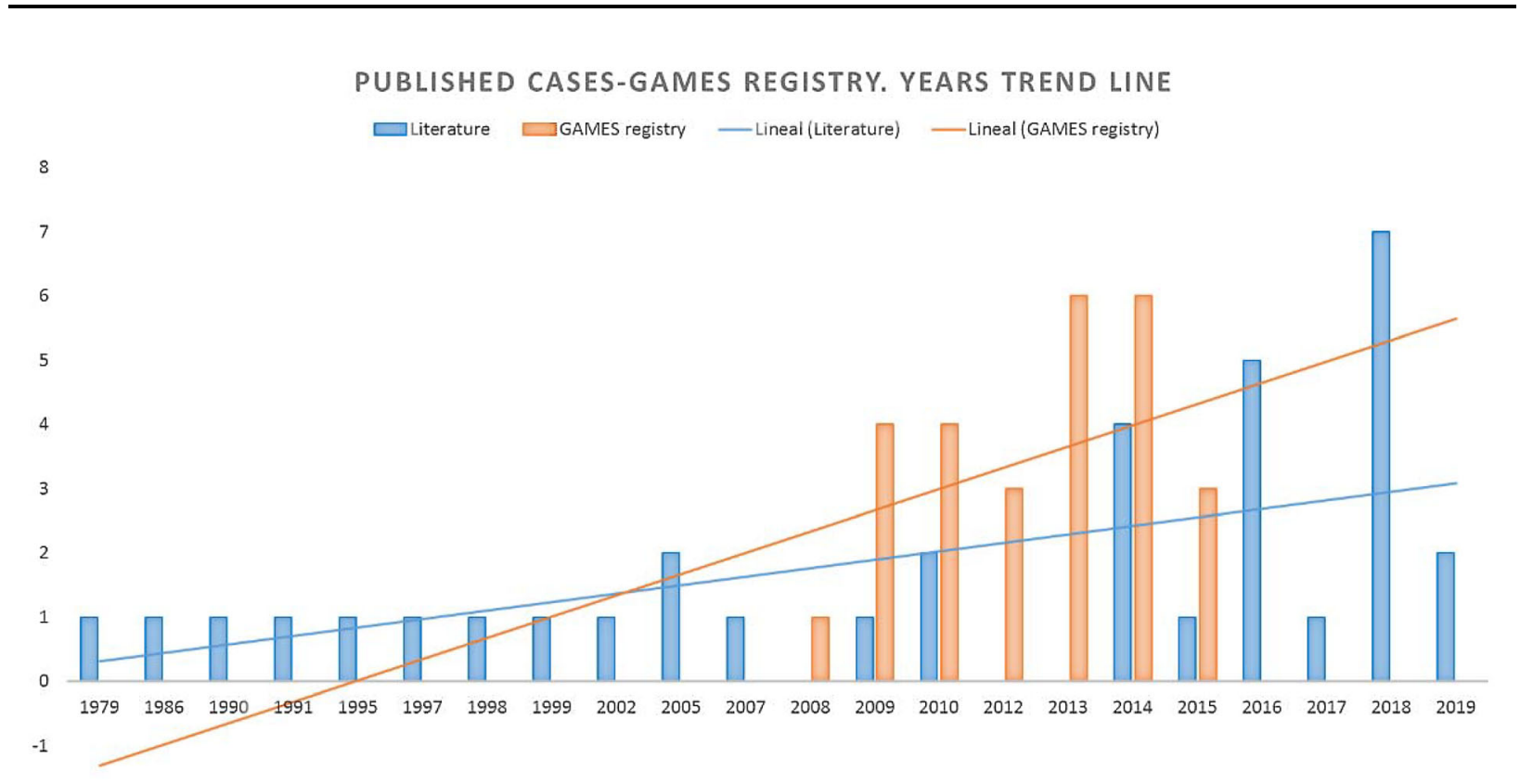

Fig. 2 Distribution by calendar year of the cases of mural endocarditis from the literature (blue) and those from the GAMES registry (orange)

\section{GAMES}

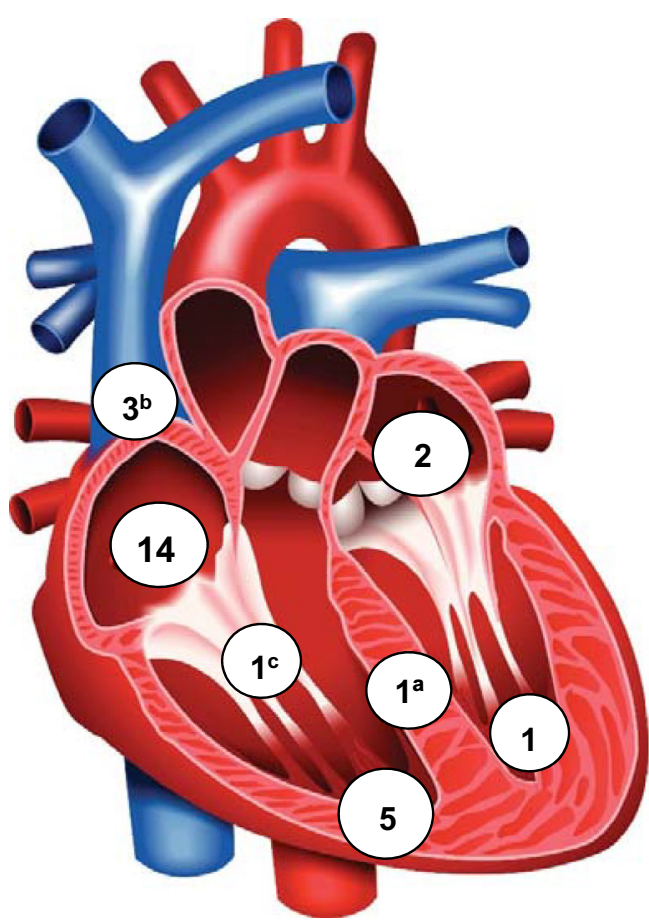

LITERATURE

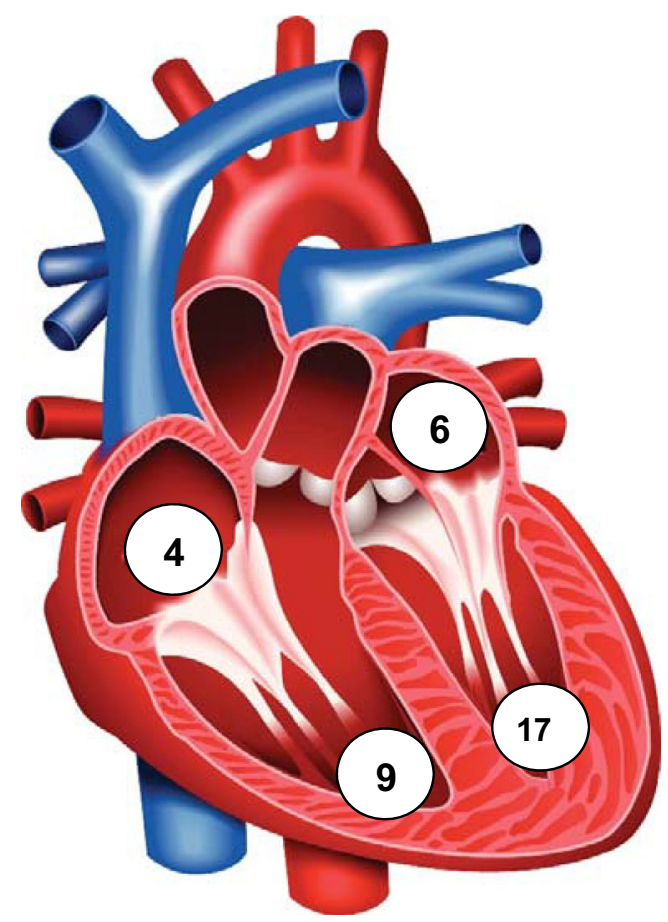

Fig. 3 Location of mural endocarditis. a: Septum. b: Vena cava. c: Tendinous chords. A GAMES, B literature 
The vegetations were significantly larger in MIE, with a mean size of $22 \mathrm{~mm}$ compared to 12 and $10 \mathrm{~mm}$ in the DIE and VIE groups, respectively $(p<0.01)$.

Regarding complications associated with endocarditis, presence of intra-cardiac complications was significantly higher in VIE with $33.9 \%$ compared to $3.7 \%$ in MIE and in DIE each $(p<0.01)$. Likewise, systemic complications such as heart failure or central nervous system involvement were more frequent in VIE $(p<0.01$ and $p=0.041)$; however, no differences were found in other complications such as acute renal failure, sepsis or septic shock.

Surgical indications were the same for all types of endocarditis and included: severe heart failure, septic shock, recurrent emboli, severe valve dysfunction, intracardiac complications (abscess), prosthetic valve infection, and large mobile vegetations or persistent bacteremia despite adequate antibiotic therapy. Non-MIEs more often had a surgical indication $(65.3 \%$ in VIE and $82.8 \%$ in DIE vs. $33.3 \%$ in MIE, $p<0.01)$ and were operated on $(42.6 \%$ in VIE and $77.1 \%$ in DIE vs. $18.5 \%$ in mural IE, $p<0.01)$.

No significant differences were found regarding in-hospital or 1-year mortality after the event.

\section{Characteristics and differences \\ between mural endocarditis \\ from the GAMES registry and published cases of mural endocarditis}

We retrieved 44 cases of MIE in the literature search, but only 36 had exclusive non-valvular involvement and enough information to analyze. General characteristics of MIE from GAMES and MIE published in the literature are given in Table 2 . The column on the right side of the table summarizes the characteristics of both combined.

The time span for the collection of cases from the literature (1979-2019) was much broader than the study period of cases obtained from the GAMES registry (2008-2018), including a high proportion of cases (33.3\%) diagnosed before the beginning of the GAMES registry. Figure 2 shows an increasing incidence of MIE along time.

Both series share some important characteristics such as a high proportion of fungal endocarditis and the presence of big vegetations. However, we found several relevant differences.

Patients in the literature group were younger than those in the GAMES series, with a mean age of 42.6 years versus 56.4 years $(p<0.001)$, had less frequent comorbidities as shown by a lower Charlson Index (1.3 literature vs. GAMES $4.3, p=0.000)$. Of note, cases from the literature more frequently were users of intravenous drugs as a risk behavior for endocarditis compared to those from the GAMES registry $(25 \%$ literature vs. $3.7 \%$ GAMES, $p=0.034$ ). Acquisition of endocarditis in the community was more frequent in cases from the literature $(69.4 \%$ vs. $25.9 \%)$ compared to those from GAMES, in which a nosocomial origin predominated ( $63 \%$ vs. $13.9 \%, p=0,0001)$. Likewise, catheter as the source for endocarditis was more frequent in the GAMES series $(59.3 \%$ vs. $13.9 \%$ in literature, $p=0.000$ ). Regarding the etiology of endocarditis, $S$. aureus was more frequent in the literature group (50\% vs. $14.8 \%$ in GAMES, $p=0.007$ ) whereas coagulase-negative staphylococci were found in GAMES series but not in the literature series $(14.8 \%$ vs. $0 \%$ in literature, $p=0.035$ ), with significant differences. The most frequent location in the case of MIE in the literature was the left ventricle $(47.2 \%)$, while in GAMES it was the right atrium (51.9\%) (Fig. 3). Complications such as the presence of systemic embolisms and CNS involvement were more frequent in the literature group.

No significant differences were found regarding surgical indication, proportion of cases that received surgery or mortality.

\section{DISCUSSION}

Our results show that MIE represents $0.7 \%$ of endocarditis. It is often a complication of catheter use that appears in immunocompromised hospitalized patients, and fungal etiology is common. Surgery is performed less frequently 
than in non-MIE, although mortality is similar to that of other types of endocarditis.

Our series provides information about MIE prevalence among total cases of endocarditis. There is no prior published large series of MIE. MIE is a rare disease, which has become easier to diagnose with the improvement in cardiac imaging techniques, which can explain in part an increasing incidence (Fig. 2). In view of the lack of prior MIE series, we decided to perform a literature review. The period of the literature review encompasses a larger period than the GAMES registry and, as such, includes earlier cases. When analyzing cases from the literature review, publication bias must be taken into consideration. Information from the GAMES together with the literature review offers a broad picture of the spectrum of MIE.

The combined data show that underlying transplantation, neoplasia and hemodialysis are prevalent in patients with MIE. The greater use of catheters in this type of subjects and a high use of hospital care could explain this finding. However, in the literature review, we observed a high proportion of community-acquired cases with a different clinical phenotype: intravenous drug users with $S$. aureus endocarditis. The high prevalence of parenteral drug users in case reports collected in the literature review may be related to the period in which the cases were described, a time when this activity was more common than nowadays. This suggests a shift in the epidemiology of MIE along time, with a decrease in IVDUs in favor of nosocomial endocarditis in which catheters appear to be implicated in the pathogenesis of MIE. The same applies to the change in the location of the vegetations in MIE [23, 24]. In contrast to VIE, where valvular endocardium is extensively exposed to damage from the bloodstream, we hypothesize that mural endocardium requires external damage, for instance, by the catheter jet, to start the process of developing a vegetation as has been described in other cases with endocardial damage caused by a jet [4, 17, 25-27].

In MIE, vegetations were larger compared to non-MIE. Regarding large vegetations, MIE diagnosis in earlier cases from the literature series often came only after embolism had already occurred. As the valvular apparatus is spared, heart failure symptoms cannot be expected to unveil the presence of endocarditis. The delay in the diagnosis of MIE implies a longer time of growth for the vegetations. The diagnostic delay in older cases, in keeping with worse imaging techniques, can explain a higher prevalence of embolisms and CNS involvement in the literature cases together with publication bias. It could be expected that, due to the larger size of the vegetations, significant differences between MIE and non-MIE regarding persistent bacteremia and systemic complications of endocarditis such as embolisms would be encountered; however, we did not find such differences.

Regarding etiology, the most common pathogens in MIE were Staphylococci and Streptococci, but we found a striking prevalence of fungi compared to non-MIE [23]. Fungal endocarditis was represented mainly by Candida and, to a lesser extent, by Aspergillus [2, 7-12]. In earlier cases of endocarditis associated with intravenous drug use, Candida has been related to injection of brown heroin diluted in fresh lemon juice [28]. In addition, candidemia is also prevalent among catheter users, leading to the development of endocarditis in the long term. Fungal endocarditis also develops in immunocompromised hosts; in particular, Aspergillus spp. endocarditis has been associated with transplantation [29]. Fungal IE often cause large vegetations $[8,12,30,31]$.

Heart failure and valvular dysfunction are relevant indications for surgery. We consider that, since MIE does not involve heart valves, these complications are less frequent, which is a possible explanation for the surgery not being indicated in as many cases of MIE as it was in other types of endocarditis. Although cardiac complications of MIE were less frequent and surgery was less commonly indicated, mortality was very similar to that of non-MIE, which underlines the importance of MIE diagnosis and correct management. 


\section{Strengths and limitations}

The present study analyzes a multicenter series from the entire Spanish territory and over a long period of time and is complemented with a review of the literature. We believe it presents a comprehensive image of MIE. Cases from the GAMES registry are collected prospectively, according to pre-established criteria, and evaluated by a multidisciplinary team, which allows putting the prevalence of this rare disease in perspective and provides a broad set of data to describe this population. Regarding series of cases from the literature, incidence or prevalence data cannot be obtained, as the total population with endocarditis is unknown, and publication bias has to be considered, so that information obtained from these cases must be evaluated with caution. Information about published cases is seldom complete. Nevertheless, that series covers a large period and is a thorough sample, which provides very valuable information to enrich the information about MIE.

\section{CONCLUSION}

Mural endocarditis is a rare but increasingly recognized and reported health care-associated disease that requires a high index of suspicion and a multidisciplinary approach to avoid the relevant morbidity and mortality.

Our results highlight the importance of this type of endocarditis in association with intravascular catheters and immunocompromised patients and, as such, with a potential for prevention.

\section{ACKNOWLEDGEMENTS}

We thank the members of the GAMES study group for their contribution to the work: Hospital Costa del Sol, (Marbella): Fernando Fernández-Sánchez, José $\mathrm{M}^{\mathrm{a}}$ García de Lomas, Gabriel Rosas, Javier de la Torre Lima; Hospital Universitario de Cruces, (Bilbao): Elena Bereciartua, María José Blanco-Vidal, Roberto
Blanco, María Victoria Boado, Marta CampañaLázaro, Alejandro Crespo, Laura Guio-Carrión, Mikel del Álamo Martínez-Lagos, Gorane EubaUgarte, Ane Josune Goikoetxea, Marta IbarrolaHierro, José Ramón Iruretagoyena, Josu IrurzunZuazabal, Leire López-Soria, Miguel Montejo, Javier Nieto, David Rodrigo, Regino Rodríguez, Yolanda Vitoria, Roberto Voces; Hospital Universitario Virgen de la Victoria, (Málaga): $\mathrm{M}^{\mathrm{a}}$ Victoria García-López, Radka Ivanova Georgieva, Guillermo Ojeda, Isabel Rodríguez-Bailón, Josefa Ruiz-Morales; Hospital Universitario Donostia-Poliklínica Gipuzkoa-IIS Biodonostia, (San Sebastián): Harkaitz Azkune-Galparsoro, Elisa Berritu-Boronat, $\mathrm{M}^{\mathrm{a}}$ Jesús Bustinduy-Odriozola, Cristina del Bosque Martín, Tomás Echeverría, Alberto Eizaguirre-Yarza, Ana Fuentes, Miguel Ángel Goenaga, Muskilda Goyeneche del Río, Ángela Granda-Bauza, José Antonio Iribarren, Xabier Kortajarena-Urkola, José Ignacio Pérez-Moreiras López, Ainhoa Rengel-Jiménez, Karlos Reviejo, Alberto SáezBerbejillo, Elou Sánchez-Haza, Rosa SebastiánAlda, Itziar Solla-Ruiz, Irati Unamuno-Ugartemendia, Diego Vicente Anza, Iñaki VillanuevaBenito, Mar Zabalo-Arrieta; Hospital General Universitario de Alicante, (Alicante): Rafael Carrasco, Vicente Climent, Patricio Llamas, Esperanza Merino, Joaquín Plazas, Sergio Reus; Complejo Hospitalario Universitario A Coruña, (A Coruña): Nemesio Álvarez, José María BravoFerrer, Laura Castelo, José Cuenca, Pedro Llinares, Enrique Miguez-Rey, María RodríguezMayo, Efrén Sánchez, Dolores Sousa-Regueiro; Complejo Hospitalario Universitario de Huelva, (Huelva): Francisco Javier Martínez; Hospital Universitario de Canarias, (Canarias): $\mathrm{M}^{\mathrm{a}}$ del Mar Alonso, Beatriz Castro, Teresa DelgadoMelian, Javier Fernández-Sarabia, Dácil GarcíaRosado, Julia González-González, Juan Lacalzada, Lissete Lorenzo de la Peña, Alina PérezRamírez, Pablo Prada-Arrondo, Fermín Rodríguez-Moreno; Hospital Regional Universitario de Málaga, (Málaga): Antonio Plata-Ciezar, José $\mathrm{M}^{\mathrm{a}}$ Reguera-Iglesias; Hospital Universitario Central Asturias, (Oviedo): Víctor AsensiÁlvarez, Carlos Costas, Jesús de la Hera, Jonnathan Fernández-Suárez, Lisardo IglesiasFraile, Víctor León-Arguero, José López-Menéndez, Pilar Mencia-Bajo, Carlos Morales, Alfonso 
Moreno-Torrico, Carmen Palomo, Begoña PayaMartínez, Ángeles Rodríguez-Esteban, Raquel Rodríguez-García, Mauricio Telenti-Asensio; Hospital Clínic-IDIBAPS, Universidad de Barcelona, (Barcelona): Manuel Almela, Juan Ambrosioni, Manuel Azqueta, Mercè Brunet, Marta Bodro, Ramón Cartañá, Carlos Falces, Guillermina Fita, David Fuster, Cristina García de la Mària, Delia García i Pares, Marta Hernández-Meneses, Jaume Llopis-Pérez, Francesc Marco, José M. Miró, Asunción Moreno, David Nicolás, Salvador Ninot, Eduardo Quintana, Carlos Paré, Daniel Pereda, Juan M. Pericás, José L. Pomar, José Ramírez, Irene Rovira, Elena Sandoval, Marta Sitges, Dolors Soy, Adrián Téllez, José M. Tolosana, Bárbara Vidal, Jordi Vila; Hospital General Universitario Gregorio Marañón, (Madrid): Iván Adán, Juan Carlos Alonso, Ana Álvarez-Uría, Javier Bermejo, Emilio Bouza, Gregorio Cuerpo-Caballero, Antonia Delgado-Montero, Ana González-Mansilla, $\mathrm{M}^{\mathrm{a}}$ Eugenia García-Leoni, Esther Gargallo, Víctor González-Ramallo, Martha Kestler-Hernández, Amaia Mari Hualde, Marina Machado, Mercedes Marín, Manuel Martínez-Sellés, Patricia Muñoz, María Olmedo, Álvaro Pedraz, Blanca Pinilla, Ángel Pinto, Cristina Rincón, Hugo RodríguezAbella, Marta Rodríguez-Créixems, Antonio Segado, Neera Toledo, Maricela Valerio, Pilar Vázquez, Eduardo Verde-Moreno; Hospital Universitario La Paz, (Madrid): Isabel Antorrena, Belén Loeches, Mar Moreno, Ulises Ramírez, Verónica Rial-Bastón, María Romero, Sandra Rosillo; Hospital Universitario Marqués de Valdecilla, (Santander): Hospital Universitario Marqués de Valdecilla, (Santander): Jesús Agüero-Balbín, Cristina Amado, Carlos Armiñanzas-Castillo, Ana Arnaiz, Francisco Arnaiz de las Revillas, Manuel Cobo Belaustegui, María Carmen Fariñas, Concepción FariñasÁlvarez, Marta Fernández-Sampedro, Iván García, Claudia González-Rico, Laura GutierrezFernandez, Manuel Gutiérrez-Cuadra, José Gutiérrez-Díez, Marcos Pajarón, José Antonio Parra, Ramón Teira, Jesús Zarauza; Hospital Universitario Puerta de Hierro, (Madrid): Jorge Calderón-Parra, Marta Cobo, Fernando Domínguez, Pablo García-Pavía, Ana FernándezCruz, Antonio Ramos-Martínez, Isabel SánchezRomero; Hospital Universitario Ramón y Cajal,
(Madrid): Tomasa Centella, José Manuel Hermida, José Luis Moya, Pilar Martín-Dávila, Enrique Navas, Enrique Oliva, Alejandro del Río, Jorge Rodríguez-Roda Stuart, Soledad Ruiz; Hospital Universitario Virgen de las Nieves, (Granada): Carmen Hidalgo-Tenorio; Hospital Universitario Virgen Macarena, (Sevilla): Manuel Almendro-Delia, Omar Araji, José Miguel Barquero, Román Calvo-Jambrina, Marina de Cueto, Juan Gálvez-Acebal, Irene Méndez, Isabel Morales, Luis Eduardo López-Cortés; Hospital Universitario Virgen del Rocío, (Sevilla): Arístides de Alarcón, Encarnación GutiérrezCarretero, José Antonio Lepe, José López-Haldón, Rafael Luque-Márquez, Guillermo Marín, Antonio Ortiz-Carrellán, Eladio Sánchez-Domínguez; Hospital San Pedro, (Logroño): Luis Javier Alonso, Pedro Azcárate, José Manuel Azcona-Gutiérrez, José Ramón Blanco, Antonio Cabrera-Villegas, Lara García-Álvarez, Concepción García-García, José Antonio Oteo; Hospital de la Santa Creu i Sant Pau, (Barcelona): Natividad de Benito, Mercé Gurguí, Cristina Pacho, Roser Pericas, Guillem Pons; Complejo Hospitalario Universitario de Santiago de Compostela, (A Coruña): M. Álvarez, A. L. Fernández, Amparo Martínez, A. Prieto, Benito Regueiro, E. Tijeira, Marino Vega; Hospital Santiago Apóstol, (Vitoria): Andrés CanutBlasco, José Cordo Mollar, Juan Carlos Gainzarain-Arana, Oscar García-Uriarte, Alejandro Martín-López, Zuriñe Ortiz de Zárate, José Antonio Urturi-Matos; Hospital SAS Línea de la Concepción, (Cádiz): Antonio Sánchez-Porto, Alejandro Úbeda-Iglesias; Hospital Clínico Universitario Virgen de la Arrixaca (Murcia): José $\mathrm{M}^{\mathrm{a}}$ Arribas-Leal, Elisa García-Vázquez, Alicia Hernández-Torres, Ana Blázquez, Gonzalo de la Morena Valenzuela; Hospital de Txagorritxu, (Vitoria): Ángel Alonso, Javier Aramburu, Felicitas Elena Calvo, Anai Moreno-Rodríguez, Paola Tarabini-Castellani; Hospital Virgen de la Salud, (Toledo): Eva Heredero-Gálvez, Carolina Maicas-Bellido, José Largo-Pau, $\mathrm{M}^{\mathrm{a}}$ Antonia Sepúlveda, Pilar Toledano-Sierra, Sadaf Zafar Iqbal-Mirza; Hospital Rafael Méndez, (LorcaMurcia):, Eva Cascales-Alcolea, Ivan KeituqwaYañez, Julián Navarro-Martínez, Ana PeláezBallesta; Hospital Universitario San Cecilio (Granada): Eduardo Moreno-Escobar, Alejandro 
Peña-Monje, Valme Sánchez-Cabrera, David Vinuesa-García; Hospital Son Llátzer (Palma de Mallorca): María Arrizabalaga-Asenjo, Carmen Cifuentes-Luna, Juana Núñez-Morcillo, $\mathrm{M}^{\mathrm{a}}$ Cruz Pérez-Seco, Aroa Villoslada-Gelabert; Hospital Universitario Miguel Servet (Zaragoza): Carmen Aured-Guallar, Nuria Fernández-Abad, Pilar García-Mangas, Marta Matamala-Adell, M $^{\mathrm{a}}$ Pilar Palacián-Ruiz, Juan Carlos Porres; Hospital General Universitario Santa Lucía (Cartagena): Begoña Alcaraz-Vidal, Nazaret Cobos-Trigueros, María Jesús Del Amor Espín, José Antonio Giner-Caro, Roberto Jiménez-Sánchez, Amaya Jimeno-Almazán, Alejandro Ortín-Freire, Monserrat Viqueira-González; Hospital Universitario Son Espases (Palma de Mallorca): Pere PericásRamis, $\mathrm{M}^{\mathrm{a}}$ Ángels Ribas-Blanco, Enrique Ruiz de Gopegui Bordes, Laura Vidal-Bonet; Complejo Hospitalario Universitario de Albacete (Albacete): $\mathrm{M}^{\mathrm{a}}$ Carmen Bellón-Munera, Elena Escribano-Garaizabal, Antonia Tercero-Martínez, Juan Carlos Segura-Luque; Hospital Universitario Terrassa: Cristina Badía, Lucía Boix-Palop, Mariona Xercavins, Sónia Ibars. Hospital Universitario Dr. Negrín (Gran Canaria): Xerach Bosch, Eloy Gómez-Nebreda, Ibalia Horcajada-Herrera, Irene Menduiña-Gallego, Imanol Pulido; Complejo Hospitalario Universitario Insular Materno Infantil (Las Palmas de Gran Canaria): Héctor Marrero-Santiago, Isabel de Miguel Martínez, Elena Pisos-Álamo. Hospital Universitario 12 de Octubre (Madrid): Eva Ma Aguilar-Blanco, Mercedes Catalán-González, María Angélica Corres-Peiretti, Andrea Eixerés-Esteve, Laura Domínguez-Pérez, Santiago de Cossío Tejido, Francisco Galván-Román, José Antonio García-Robles, Francisco LópezMedrano, $\mathrm{M}^{\mathrm{a}}$ Jesús López-Gude, $\mathrm{M}^{\mathrm{a}}$ Ángeles Orellana-Miguel, Patrick Pilkington, Yolanda Revilla-Ostalaza, Juan Ruiz Morales, Sebastián Ruiz-Solís, Ana Sabín Collado, Marcos SánchezFernández, Javier Solera Rallo, Jorge Solís Martín. Hospital Universitari de Bellvitge (L'Hospitalet de Llobregat): Guillermo Cuervo, Francesc Escrihuela-Vidal, Jordi Carratalà, Inmaculada Grau, Sara Grillo, Carmen Ardanuy, Dámaris Berbel, José Carlos Sánchez-Salado, Oriol Alegre, Alejandro Ruiz-Majoral, Fabrizio Sbraga, Arnau Blasco, Laura Gracia Sánchez, Iván SánchezRodríguez. Hospital Universitario Fundación
Jiménez Díaz (Madrid): Beatriz Álvarez, Alfonso Cabello-Úbeda, Ricardo Fernández-Roblas, Miguel Ángel Navas-Lobato, Ana María Pello. Hospital Basurto (Bilbao): Mireia de la Peña Triguero, Ruth Esther Figueroa-Cerón, Lara Ruiz-Gómez. Hospital del Mar (Barcelona): Mireia Ble, Juan Pablo Horcajada-Gallego, Antonio José Ginel, Inmaculada López, Alexandra Mas, Antoni Mestres, Lluís Molina, Ramón Serrat, Núria Ribas, Francisca Sánchez, Ana Silverio, Marina Suárez, Luisa Sorlí, Lluís Recasens, Manuel Taurón.

Funding. No funding or sponsorship was received for this study or publication of this article. The Rapid Service Fee was funded by the authors.

Authorship. All named authors meet the International Committee of Medical Journal Editors (ICMJE) criteria for authorship for this article, take responsibility for the integrity of the work as a whole, and have given their approval for this version to be published.

Author Contribution. Conceptualization and study design: AF-C, PM. Methodology: AFC, AG-V. Data collection: all authors. Data interpretation: AF-C, AG-V. Writing first draft: AG-V. Critical revision for important intellectual content: all authors. Final approval: All authors. All authors agree to be accountable for all aspects of the work by ensuring that questions related to the accuracy or integrity of any part of the work will be appropriately investigated and resolved. AF-C and AG-V had full access to all the data in this study and take complete responsibility for the integrity of the data and the accuracy of the data analysis.

Prior Presentation. This manuscript is based on work that has been previously presented as an oral communication at the VIIIth Congress of SEICAV (Spanish Society of Cardiovascular Infections) in Madrid, September 2019.

Disclosures. A. Gutiérrez-Villanueva, P. Muñoz, A. Delgado-Montero, M. Olmedo-Samperio, A. de Alarcón, E. Gutiérrez-Carretero, J. Zarauza, D. García i Pares, MA. Goenaga, G. 
Ojeda-Burgos, AJ. Goikoetxea-Agirre, JM. Reguera-Iglesias, A. Ramos and A. FernándezCruz have nothing to disclose.

Compliance with Ethics Guidelines. The study and the common case report form were approved by the local and national institutional review boards and ethics committees (Comité ético de Investigación Clínica Regional de la Comunidad de Madrid CEIC_R; EC 18/07; date 11/01/2008).

Data Availability. The datasets generated during and/or analysed during the current study are available from the corresponding author on reasonable request.

Open Access. This article is licensed under a Creative Commons Attribution-NonCommercial 4.0 International License, which permits any non-commercial use, sharing, adaptation, distribution and reproduction in any medium or format, as long as you give appropriate credit to the original author(s) and the source, provide a link to the Creative Commons licence, and indicate if changes were made. The images or other third party material in this article are included in the article's Creative Commons licence, unless indicated otherwise in a credit line to the material. If material is not included in the article's Creative Commons licence and your intended use is not permitted by statutory regulation or exceeds the permitted use, you will need to obtain permission directly from the copyright holder. To view a copy of this licence, visit http:// creativecommons.org/licenses/by-nc/4.0/.

\section{REFERENCES}

1. Patel M, Ahmad Z, Distler E, Swofford B. The use of cardiac MRI in a rare case of primary mural endocarditis. BMJ Case Rep. 2017; 2017

2. Lopez-Ciudad V, Castro-Orjales MJ, Leon C, SanzRodriguez C, de Torre-Fernandez MJ, Perez de JuanRomero MA, et al. Successful treatment of Candida parapsilosis mural endocarditis with combined caspofungin and voriconazole. BMC Infect Dis. 2006;6:73.
3. Ak K, Adademir T, Isbir S, Arsan S. Right ventricular mural endocarditis presenting as an isolated apical mass in a non-addict patient with congenital deafness and aphasia. Interact Cardiovasc Thorac Surg. 2009;8(4):498-500.

4. Hosokawa S, Okayama H, Hiasa G, Kawamura G, Shigematsu T, Takahashi T, et al. Isolated left atrial infective mural endocarditis. Intern Med. 2018;57(7):957-60.

5. Adel A, Jones E, Johns J, Farouque O, Calafiore P. Bacterial mural endocarditis. A case series. Heart Lung Circ. 2014;23(8):e172-9.

6. Tahara M, Nagai T, Takase Y, Takiguchi S, Tanaka Y, Kunihara $\mathrm{T}$, et al. Primary mural endocarditis without valvular involvement. J Ultrasound Med. 2017;36(3):659-64.

7. Mullen P, Jude C, Borkon M, Porterfield J, Walsh TJ. Aspergillus mural endocarditis. Clin Echocardiogr Diagn Chest. 1986;90(3):451-2.

8. Kim KC, Choi HM, Yoon YE, Cho Y, Cho GY. A case of aspergillus mural endocarditis presenting with complete atrioventricular block after liver-kidney transplantation. CASE (Phila). 2019;3(6):267-71.

9. Lim ML, Oliver DH, Barasch E. Aspergillus mural vegetation identified by transesophageal echocardiography. Echocardiography. 1997;14(3):283-6.

10. Leung WH, Lau CP, Tai YT, Wong CK, Cheng CH. Candida right ventricular mural endocarditis complicating indwelling right atrial catheter. Chest. 1990;97(6):1492-3.

11. Granados JM, Ayestaran OS, Gaboli M, Fernandezde Miguel S, Gomezdeuero MP. Combined antifungal therapy. Treatment success in a case of mural endocarditis due to Candida glabrata. An Pediatr (Barc). 2009;71(4):368-9.

12. Pavlina AA, Peacock JW, Ranginwala SA, Pavlina PM, Ahier J, Hanak CR. Aspergillus mural endocarditis presenting with multiple cerebral abscesses. J Cardiothorac Surg. 2018;13(1):107.

13. Ruiz RS, San Roman JA, Alonso JR, Fernandez-Aviles F. Acute myocardial infarction secondary to left atrial mural endocarditis. Echocardiography. 2005;22(7):621-2.

14. Shirani J, Keffler K, Gerszten E, Gbur CS, Arrowood JA. Primary left ventricular mural endocarditis diagnosed by transesophageal echocardiography. J Am Soc Echocardiogr. 1995;8(4):554-6.

15. Rutlen C, Vallurupalli S. Chamber-made: mural endocarditis. Am J Med. 2018;131(8):918-21. 
16. Neoh K, Khan JN, Albouaini K, Chenzbraun A. Biventricular mural vegetations without valvular involvement: an unusual presentation of Staphylococcus aureus endocarditis. Echo Res Pract. 2018;5(4):I11-3.

17. Fyfe B, Ianosi-Irimie $M$, Motavalli L. Infective endocarditis complicating hypertrophic obstructive cardiomyopathy: an unusual mural pattern. Cardiovasc Pathol. 2010;19(1):e5-7.

18. Wilson AM, Lu YR. Two cases of right atrial mural endocarditis caused by Staphylococcus Aureus. Heart Lung Circ. 2016;25(10):e119-21.

19. Li JS, Sexton DJ, Mick N, Nettles R, Fowler VG Jr, Ryan T, et al. Proposed modifications to the Duke criteria for the diagnosis of infective endocarditis. Clin Infect Dis. 2000;30(4):633-8.

20. Charlson ME, Pompei P, Ales KL, MacKenzie CR. A new method of classifying prognostic comorbidity in longitudinal studies: development and validation. J Chronic Dis. 1987;40(5):373-83.

21. Murdoch DR, Corey GR, Hoen B, Miro JM, Fowler VG Jr, Bayer AS, et al. Clinical presentation, etiology, and outcome of infective endocarditis in the 21st century: the International Collaboration on Endocarditis-Prospective Cohort Study. Arch Intern Med. 2009;169(5):463-73.

22. Habib G, Lancellotti P, Antunes MJ, Bongiorni MG, Casalta JP, Del Zotti F, et al. ESC Guidelines for the management of infective endocarditis: the task force for the management of infective endocarditis of the European Society of Cardiology (ESC). endorsed by: European association for cardio-thoracic surgery (EACTS), the European association of nuclear medicine (EANM). Eur Heart J. 2015;36(44): 3075-128.

23. Ortega-Loubon C, Munoz-Moreno MF, AndresGarcia I, Alvarez FJ, Gomez-Sanchez E, Bustamante-
Munguira J, et al. Nosocomial vs. community-acquired infective endocarditis in Spain: location, trends, clinical presentation, etiology, and survival in the 21st century. J Clin Med. 2019;8(10):1755.

24. Hwang JW, Park SW, Cho EJ, Lee GY, Kim EK, Chang SA, et al. Risk factors for poor prognosis in nosocomial infective endocarditis. Korean J Intern Med. 2018;33(1):102-12.

25. Lee KY, Yi JE, Moon D, Jung HO, Youn HJ, Lim J, et al. Isolated right-sided mural infective endocarditis in a 32-year-old woman with muscular ventricular septal defect. Cardiology. 2014;129(1): $65-8$.

26. Ringer M, Feen DJ, Drapkin MS. Mitral valve prolapse: jet stream causing mural endocarditis. Am J Cardiol. 1980;45(2):383-5.

27. Gonzalez-Lavin L, Lise M, Ross D. The importance of the "jet lesion" in bacterial endocarditis involving the left heart. Surgical considerations. J Thorac Cardiovasc Surg. 1970;59(2):185-92.

28. Bisbe J, Miro JM, Latorre X, Moreno A, Mallolas J, Gatell JM, et al. Disseminated candidiasis in addicts who use brown heroin: report of 83 cases and review. Clin Infect Dis. 1992;15(6):910-23.

29. Ioannou P, Papakitsou I, Kofteridis DP. Fungal endocarditis in transplant recipients: a systematic review. Mycoses. 2020;63(9):952-63.

30. Badiee P, Amirghofran AA, Ghazi NM. Evaluation of noninvasive methods for the diagnosis of fungal endocarditis. Med Mycol. 2014;52(5):530-6.

31. Leite-Andrade $\mathrm{MC}$, Inacio $\mathrm{CP}$, Calixto $\mathrm{F}$, Feitosa $\mathrm{M}$, Sepulveda DPL, Santos FAG, et al. Large aortic prosthesis fungal vegetation due to candida parapsilosis: an uncommon presentation. Mycopathologia. 2019;184(6):795-6. 